Implementasi Nilai-Nilai Pendidikan... | 59

\title{
IMPLEMENTASI NILAI-NILAI PENDIDIKAN AKHLAK RASUL DALAM PENGAJIAN KITAB MAULID SHIMT AD-DURAR TERHADAP AKHLAK SANTRI DI PONDOK PESANTREN DARUR ROHMAN DEMAK
}

\author{
Muhamad Ulil Albab 1) * \\ ${ }^{1}$ Program Studi Pendidikan Agama Islam, Fakultas Agama Islam \\ Universitas Islam Sultan Agung, Semarang \\ *E-mail: ulilmuhammad63@gmail.com
}

\begin{abstract}
This research aims to implement the values of moral education of the Apostle in the study of Mawlid SHIMT Ad-Durar to students in the boarding school in Darur Rohman Demak. Implementation of the value of moral education of the Apostle in the book Shimt al-Durar mawlid on the students in the boarding school Darur Rohman, has been performed well in the boarding school environment especially on the daily activities of students in the area of the cottage that is in place of morality. According to the display in the book of Shimt al-Durar mawlid when it will do anything especially when willing to learn him, he has always had the holy first, read the prayer and that is very important using morality. His habit was implemented at the boarding school Darur Rohman. The values of moral education in it are teaching the students to become people who have the moral sense of the prophet is with a sense of love and glorify him, say Sholawat and greetings to him. And teach the students to be people who have a sense of self-esteem that is by maintaining the purity of birth and inner and refraining from something that is not liked by Allah SWT, has a sense of shame, weak and gentle tempers, have a strong determination, far-off, is generous, authoritative.
\end{abstract}

Keywords: Concept of value, Educational Morality of the Apostle, Book of Maulid SHIMT AdDurar

\begin{abstract}
Abstrak
Penelitian ini bertujuan untuk mengimplementasi nilai-nilai pendidikan akhlak rasul dalam pengajian kitab maulid Shimt Ad-Durar terhadap akhlak santri di pondok pesantren Darur Rohman Demak. Implementasi nlai-nilai pendidikan akhlak rasul dalam kitab maulid Shimt adDurar terhadap akhlak santri di pondok pesantren Darur Rohman, telah dilaksanakan dengan baik di lingkungan pondok pesantren khususnya pada aktifitas keseharian santri di lingkup pondok yang mengedepankan akhlak. Sesuai dengan yang di paparkan dalam kitab maulid Shimt ad-Durar ketika akan berbuat apapun khususnya ketika mau belajar beliau al-Habib Ali selalu bersuci terlebih dahulu, membaca do'a dan yang sangat penting menggunakan akhlak. Kebiasaan yang dilakukan beliau, pada saat itu di implementasikan di pondok pesantren Darur Rohman. Nilai-nilai pendidikan akhlak yang ada di dalamnya adalah mengajari para santri agar menjadi orang yang memiliki rasa akhlak terhadap Rasulullah Saw yaitu dengan rasa mencintai dan memuliakannya, mengucapkan sholawat dan salam kepadanya. Dan mengajari para santri agar menjadi orang yang memiliki rasa akhlak terhadap dirinya sendiri yaitu dengan cara memelihara kesucian lahir serta batin dan menahan diri dari sesuatu yang tidak disukai oleh Allah Swt, mempunyai rasa malu, berperangai yang lemah serta lembut, mempunyai tekad yang kuat, bersifar zuhud, bersifat dermawan, berwibawa.
\end{abstract}

Kata Kunci: Konsep Nilai, Pendidikan Akhlak Rasul, Kitab Maulid Shimt Ad-Durar 


\section{PENDAHULUAN}

Islam adalah agama yang sangat mengedepankan nilai-nilai akhlak, sesuai akhlak terhadap Rasuullah Saw dengan mencintai Rasululah secara tulus dengan mengikuti semua apa yang menjadi sunnahnya, Dalam diri Rasulullah Saw terdapat suri tauladan yang baik dan menjadikannya panutan. Beliau mempunyai perilaku yang santun dalam kehidupan sehari-harinya, selalu mencontohkan kepada para sahabatnya akhlak yang mulia, yaitu akhlak Al-Qur'an. Hal tersebut telah dinyatakan Allah SWT:

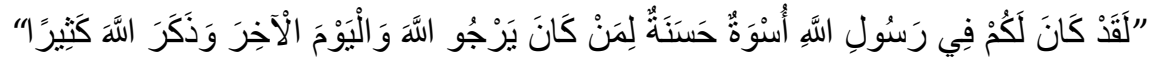

"Sesungguhnya telah ada pada (diri) Rasulullah itu suri teladan yang baik bagimu (yaitu) bagi orang yang mengharap (rahmat) Allah dan (kedatangan) hari kiamat dan dia banyak menyebut Allah."(QS. Al-Ahzab: 21) (Departemen Agama RI, Al-Qur'an dan Tafsirnya, Jakarta: Lembaga Percetakan Al-Qur'an Departemen Agama 2009, Jilid VII, hlm, 638.)

Secara garis besar akhlak dapat dibagi menjadi dua bagian, yang pertama yaitu akhlak yang terpuji (al-Akhlak al-Karimah atau al-Mahmudah), adalah akhlak yang senantiasa berada dalam kontrol Ilahiyah yang dapat membawa nilai-nilai positif dan kondusif bagi kemaslahatan umat, seperti sabar, jujur, ikhlas, bersyukur, rendah hati (tawadlu), berprasangka baik (husnudzon), optimis, suka menolong orang lain, suka bekerja keras dan lain-lain. Kedua yaitu akhlak yang tercela (al-Akhlak alMadzmumah), adalah akhlak yang tidak dalam kontrol Ilahiyah, atau berasal dari hawa nafsu yang berada dalam lingkaran syaitiniyah dan dapat membawa suasana negatif serta destruktif bagi kepentingan manusia, seperti sombong (takabbur), berperasangka buruk (su'udzon), tamak, pesimis, dusta, kufur, berkhianat, malas, dan lain-lain. (Aminuddin, dkk. Pendidikan Agama Islam Untuk Perguruan Tinggi Umum, (Bogor: Ghalia, 2014), hlm, 153.)

Menurut para ulama Islam yang cenderung untuk mempelajari tentang akhlak, seperti Ibn Maskawaih, Ibnu Sina dan al-Ghozali, bahwa akhlak dapat dibentuk melalui pendidikan, latihan, pembinaan dan perjuangan keras serta sungguh-sungguh, namun ada juga yang berpendapat bahwa akhlak tidak dapat dibentuk karena akhlak merupakan insting (gharizah) yang sudah dibawa manusia sejak lahir, namun pendapat ini dibantah oleh Yusuf Qardhawi, beliau mengatakan bahwa dorongan insting dan nafsu dapat dikendalikan dengan iman. 
Akal yang digunakan secara adil akan menimbulkan hikmah, sedangkan amarah yang digunakan secara adil akan menimbulkan sikap perwira, dan nafsu syahwat yang digunakan secara adil akan menibukan iffah, yaitu dapat memelihara diri dari perbuatan dosa maupun maksiat, dengan demikian inti akhlak pada akhirnya bermuara pada sikap adil dalam mempergunakan potensi rohaniyah yang dimiliki manusia.

Di Indonesia sendiri, peringatan maulid nabi sudah masyhur dan sangat melembaga bahkan telah ditetapkan sebagai hari libur nasional. Setiap memasuki bulan maulud (Rabi'ul Awwal), berbagai organisasi masyarakat, jam'iyyah serta tempat-tempat seperti musholla, masjid, institusi pendidikan, majelis ta'lim, pondok pesantren dan majelis dzikir sudah bersiap untuk memperingatinya dengan beragam cara, dari yang hanya sekedar membaca kitab maulid Nabi seperti kitab maulid alBarzanji, kitab maulid ad-dziba'i, dan kitab maulid shimt ad-durar ataupun menggelar pengajian akbar yang mengundang para habaib, seperti Habib syech bin Abdul Qodir as-Segaff, Habib Ali Zaenal Abidin, dan lain-lain.

Di pondok pesantren atau di pedesaan biasanya mengadakan acara kecil-kecilan, selapanan rutin, hingga seremonial akbar dan bakti sosial. Bahkan bukan hanya setiap menjelang bulan maulud (Rabi'ul Awwal) saja, tetapi pada setiap malam jumat, malam kamis, malam senin masyarakat Indonesia pun membaca maulid Nabi khususnya di pedesaan sebagai bentuk kecintaan mereka kepada Nabi Muhammad Saw serta mencari keberkahan dan syafaat khususnya syafa'atul udzma.

Shalawat merupakan sebuah pujian atau kemuliaan kepada Nabi Muhammad Saw, yang sama seperti halnya kita mengingat (dzikir) atau berdoa kepada Allah Swt. Shalawat, jika datangnya dari Allah kepada-Nya maka bermakna rahmat dan keridhaan. Jika dari para malaikat berarti permohonan ampun, dan bila dari umatnya maka bermakna sebuah pengharapan atau sanjungan agar kerahmatan dan keridhaan Allah Swt dikekalkan.

Firman Allah SWT dalam QS. Al Ahzab: 56 yang berkaitan dengan perintah sholawat: "Sesungguhnya Allah dan malaikat-malaikat-Nya bershalawat untuk Nabi. Hai orang-orang yang beriman, bershalawatlah kamu untuk Nabi dan ucapkanlah salam penghormatan kepadanya" (QS. Al Ahzab: 56) (https://tafsirweb.com/7668surat-al-ahzab-ayat-56.html, diakses pada tanggal 26 November 2019 pukul 14:03) 
Memuji dan menyanjung Nabi Muhammad bukanlah menganggap Rasululah sebagai Tuhan, tetapi menyanjung Rasulullah adalah mengakui Muhammad Saw sebagai manusia pilihan. Shalawat tidak hanya sebuah bacaan wirid saja. Akan tetapi bisa juga sebagai doa-doa dalam kehidupan, sehingga dengan dibacakannya shalawat menjadi adat spiritual dalam memenuhi hajat-hajat manusia. Dengan lantaran (bertawasul) kepada baginda nabi Muhammad Saw adalah merupakan salah satu cara untuk mendekatkan diri kepada Allah Swt.

Kegiatan maulid nabi yang berisikan tentang pembacaan syair maulid shimt addurar, tidak hanya di negara Indonesia saja tetapi juga negara dibagian Timur Tengah. Di Indonesia sendiri khususnya orang-orang NU, membaca kitab maulid shimt ad-durar dilakukan dalam rangka kajian selapanan atau menyambut kelahiran Rasulullah, bahkan juga di pedesaan acara maulid di jadikan arisan rutinan tiap seminggu sekali di rumah-rumah sesuai urutan. Selain mauludiyah, kitab tersebut juga sering dibaca ketika ada hajat anak lahir (tasmiyahan), hajat resepsi, khitanan, bahkan masalah yang sulit di pecahkan dan musibah yang sudah berlarut-larut. Yang tidak ada maksud lain yaitu memohon berkah Rasulullah akan terkabul semua yang dihajatkan.

Di antara beberapa kitab maulid Nabi yang sudah masyhur, terdapat kitab maulid shimt ad-durar yang berartikan untaian-untaian mutiara. Kitab maulid shimt ad-durar merupakan sebuah karya tulis berupa prosa, sajak serta menggunakan bahasa arab yang indah dan enak di baca serta di dengarkan yang berisikan tentang biografi Nabi Muhammad Saw, mencakup nasabnya (silsilah), dan kehidupannya dari masa kanakkanak hingga di angkat menjadi rasul. Selain itu juga mengisahkan sifat-sifat mulia yang dimilikinya, dan juga berbagai peristiwa untuk dijadikan teladan manusia.

Nama pengarangnya adalah Al-Habib Ali bin Muhammad bin Husein Al-Habsyi, beliau seorang sufi yang lahir di Qasam yang terletak di sebuah kota di Hadramaut pada tahun 1259H/1843M dan wafat pada tahun 1333H/1915M. (Ali bin Muhammad bin Husein Al-Habsyi, Kitab Maulid Shimt Maulid ad-durar, hlm, 5.)

Kebanyakan masyarakat Arab berasumsi bahwa kitab maulid shimt ad-durar hanya sekedar di baca, enak dan merdu di dengar saja, hingga tidak mengetahui apa saja nilai-nilai yang terkandung dalam kitab maulid tersebut, begitu juga masyarakat di sekitar penulis yang belum tentu bisa membaca huruf-huruf Arab atau hanya membaca Arab latin, hal tersebut juga menjadi salah satu faktor yang menjadi penyebab tidak tahunya masyarakat tentang kandungan kitab maulid shimt ad-durar. 
Kajian di masjid, mushola, majlis, pesantren atau tempat keagamaan masyarakat disekitar penulis kebanyakan memang tentang akhlak atau akhlak tasawuf, akan tetapi kitab yang digunakan bukanlah kitab maulid shimt ad-durar melainkan seperti Ihya' Ulumuddin, Akhlak lil Baniin, Nasaih Ad diniyah dan lain-lain. Sementara kitab maulid shimt ad-durar hanya diambil (nukil) sebagian kecilnya saja ketika para habaib atau kiyai menyampaikan mauidhoh hasanah atau rutinan majlis taklim saja. Oleh karena itu tidak banyak masyarakat yang mengetahui dengan benar arti dan kandungan apa saja yang terdapat dalam kitab maulid shimt ad-durar.

\section{METODE}

Penulis dalam melaksanakan penelitian di pondok pesantren Darur rahman ini menggunakan pendekatan kualitatif, yakni prosedur penelitian yang menghasilkan data deskriptif, yaitu berupa kata-kata tertulis atau lisan dari orang-orang dan yang dapat diteliti maupun diamati, pendekatan ini diarahkan pada latar belakang individu tersebut secara menyeluruh (holistik). (Lexy J. Moleong, Metode Penelitian Kualitatif, (Bandung: PT. Remaja Rosada Karya, 2002), hlm, 79.). Jenis penelitian yang digunakan adalah jenis penelitian lapangan (field resech) dengan menggunakan pendekatan kualitatif. Aspek penelitian dari implementasi nilai-nilai pendidikan akhlak dalam kitab maulid Shimt ad-Durar yaitu: a. Metode pengajian, b. Pendidikan akhlak terhadap Allah Swt, c. Pendidikan akhlak terhadap makhluk, d. Pendidikan akhlak terhadap masyarakat. Adapun data yang digunakan penulis dalam penelitian ini adalah menggunakan data kualitatif.

Dalam penelitian ini penulis membutuhkan beberapa data yang dijadikan untuk sumber data. Data tersebut meliputi hasil wawancara yang mendalam oleh peneliti dengan narasumber tentang implementasi nilai-nilai pendidikan akhlak rasul dalam pengajian kitab maulid Shimt ad-Durar terhadap akhlak santri di pondok pesantren Darur rohman.

\section{HASIL DAN PEMBAHASAN}

\section{Pendidikan Akhlak Rasul}

Pendidikan akhlak adalah suatu kegiatan yang dilakukan secara disengaja dan sadar untuk memberikan bimbingan, baik jasmani dan juga rohani, melalui pembimbingan nilai-nilai Islam, pelatihan moral, fisik serta menghasilkan perubahan ke arah yang positif, yang nantinya dapat diaktualisasikan didalam kehidupan 
seseorang, dengan terbiasa berfikir, bertingkah laku dan berbukti pekerti yang baik menuju terbentuknya manusia yang berakhlak mulia, yang dimana dapat menghasilkan pengalaman atau perbuatan dengan mudah tanpa harus direnungkan dan sisengaja atau tanpa tidak adanya pemikiran dan pertimbangan, yakni bukan karena adanya tekanan, paksaan dari orang lain dan bahkan pengaruh-pengaruh yang indah, perbuatan tersebut harus stabil (konstan) dilakukan berulang kali dalam bentuk yang sering sehingga menjadi sebuah kebiasaan. (Raharjo, dkk., Pemikiran Pendidikan Islam; Kajian Tokoh Klasik dan Kontemporer, (Yogyakarta: Pustaka Pelajar, 1999), hlm, 63.)

Akhlak terhadap rasul yakni cinta dan taat kepadanya, maksudnya yaitu dengan cara melaksanakan segala apa yang menjadi perintahnya dan menjauhi segala apa yang menjadi larangannya, hal tersebut telah dituangkan dalam al-Hadist (sunnah) beliau yang berwujud ucapan, perbuatan dan penetapannya. Nabi Muhammad Saw adalah sebagai utusan Allah Swt yang terakhir, beliaulah imam anbiya' dan rasul, pada dirinya melekat sumber keteladanan bagi umat manusia, beliaulah yang pantas disebut induk akhlak Islami. Beliau bukan saja sebagai manusia biasa akan tetapi juga sebagai sang pemimpin, ahli medis, ekonomi, politikus, ahli militer, kepala negara, pendidik, dan lain sebagainya. (Nasharuddin, Akhlak, (Jakarta: Raja Grafindo Persada, 2015), hlm, 247.)

Pendidikan akhlak terhadap Rasulullah Saw yang harus ditanamkan yaitu; mengikuti dan mematuhi sunnah Rasulullah, memberikan penghormatan yang tinggi kepada Rasulullah, bersifat santun, mencintai Rasulullah serta bershalawat kepadanya.

\section{Kitab Maulid Shimt ad-Durar}

Kitab Maulid Shimt ad-Durar adalah sebuah karya tulis seni sastra yang memuat kehidupan Nabi Muhammad Saw. Karya sastra ini di baca dalam berbagai upacara keagamaan di dunia Islam, sebagai bagian yang menonjol dalam kehidupan agama tradisional. Dengan membacanya diharapkan dapat meningkatkan keimanan dan kecintaan terhadap Nabi Muhammad SAW.

Dalam kitab ini, sejarah hidup Rasullullah SAW tergambar, mulai dari silsilah keluarganya, kehidupannya semasa anak-anak, remaja, dan pemuda hingga diangkat menjadi nabi dan rasul. Shimt ad-Durar juga mengisahkan sifat yang dimiliki Rasulullah dan perjuangannya dalam menyiarkan Islam dan menggambarkan kepribadiannya yang agung untuk dijadikan teladan umat manusia. Nama pengarangnya adalah AlHabib Ali bin Muhammad bin Husein al-Habsyi beliau seorang sufi yang lahir di Qasam 
sebuah kota di Hadramaut pada 1259 H/1843 M dan wafat pada 1333 H/1915 M. (Ali bin Muhammad bin Husein Al-Habsyi, Untaian Mutiara Kisah Kelahiran Manusia Utama; Akhlak, Sifat dan Riwayat Hidupnya (Kisah Maulid Nabi Besar Muhammad SAW), Terj. Simtud Durar Fi Akhbar Maulid Khairil Basyar wa Ma Lahu min Akhlaq wa Aushaf wa Siyar, oleh Alwi bin Ali al-Habsyi, (Solo: Sekretariat Masjid Riyadh, 1992), Cet. II, hlm, 5.)

\section{Analisis Nilai-Nilai Pendidikan Akhlak Rasul Dalam Pengajian Kitab Maulid Shimt ad-Durar di Pondok Pesantren Darur Rohman.}

\section{Akhlak Terhadap Allah SWT}

a. Menyucikan dan Memuji-Nya

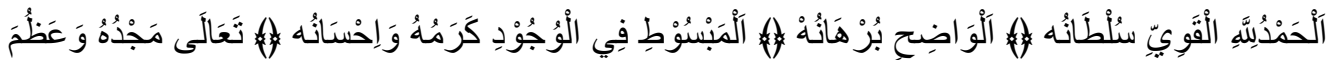

$$
\begin{aligned}
& \text { شَانَهُهْ }
\end{aligned}
$$

“Segala puji bagi Allah Yang amat teguk kekuasaan-NyaAmat jelas bukti-bukti kebenaran-Nya Terbentang luas kedermawanan dan kemurahan-Nya Maha tinggi kemuliaan-Nya dan Maha agung kedudukan-Nya". (Ali bin Muhammad bin Husein Al-Habsyi, Untaian Mutiara Kisah Kelahiran Manusia Utama; Akhlak, Sifat dan Riwayat Hidupnya (Kisah Maulid Nabi Besar Muhammad SAW), Tarjamah Simthud Durar Fi Akhbar Maulid Khairil Basyar wa Ma Lahu min Akhlaq wa Aushaf wa Siyar oleh Alwi bin Ali Al-Habsyi, (Solo: Sekretariat Masjid Riyadh, 1992), Cet. II, hlm, 1.)

Dalam setiap aktivitas atau pekerjaan supaya tidak bertentangan dengan perintah Allah Swt, penggunaan asma Allah pun dianjurkan dalam setiap aktivitas yang mempunyai nilai bermanfaat, sebagaimana yang disebutkan dalam hadist yang diriwayatkan dari Abu Hurairah ra, Rasulullah Saw. bersabda:

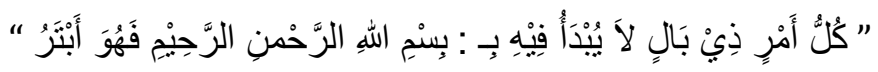

“Setiap perkara penting yang tidak dimulai dengan bismillah ar-rahmaan arraahiim amalan tersebut terputus berkahnya" (H.R Abu Dawud r.a).(HR. AlKhatib dalam Al-Jami', dari jalur Ar-Rahawai dalam Al-Arba'in, As-Subki dalam tabaqathnya.)

b. Memohon Ridho-Nya

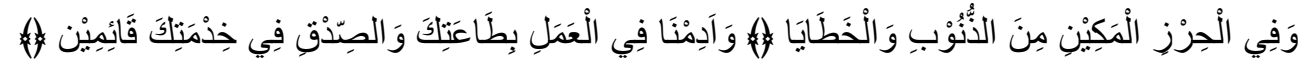


"Dan tetapkanlah diri kami dalam kepatuhan kepada-Mu dan ketulusan hati dalam beramal demi keridhaan-Mu." (Ali bin Muhammad bin Husein AlHabsyi, Kitab Maulid Shimt ad-Durar, hlm, 63.)

c. Bersyukur kepada-Nya

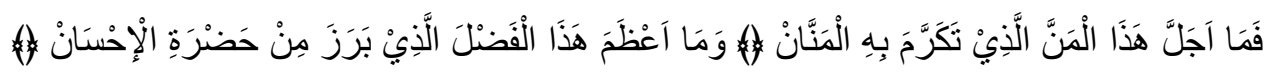

"Aduhai betapa agung sebuah anugerah ini, dilimpahkan oleh Allah Swt yang Maha Pemurah, Maha Pemberi, betapa tingginya nilai keutamaan ini datang dari Allah Swt yang sumber segala ihsan". (Ali bin Muhammad bin Husein AlHabsyi, Kitab Maulid Shimt ad-Durar, hlm, 7.)

\section{Akhlak Terhadap Makhuk}

a. Akhlak terhadap Rasulullah Saw

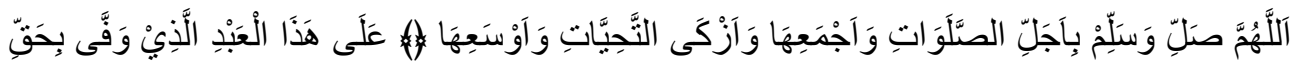

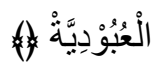

"Ya Allah ya Tuhan kami limpahkanlah shalawat dan salam yang terbesar serta mencakup segalanya. Teramat suci, luas jangkauannya atas diri insan ini”. (Ali bin Muhammad bin Husein Al-Habsyi, op.cit., hlm, 12.)

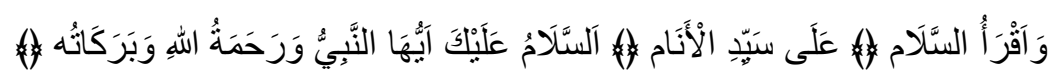

"Dan sudah sepatutnya kubacakan salam atas Nabi Muhammad Saw sebagai pemimpin penghuni alam; Assalamu'alaika ayyuha an-Nabiyyu wa rahmatullahi wa barakaatuhu".( Ibid., hlm, 56.)

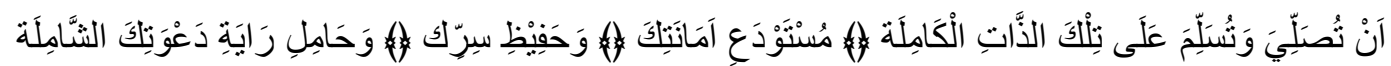
"Semoga Engkau berkenan melimpahkan shalawat dan salam atas dzat yang sempurna itu tempat penyimpananan amanah-Mu pemegang rahasia-Mu Pengibar panji dakwah-Mu" (Ibid., hlm, 58.)

b. Akhlak Terhadap Diri Sendiri

1) Malu

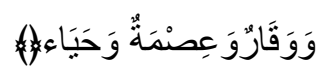

"Keanggunan, kesucian, serta rasa malu". (Ali bin Muhammad bin Husein Al-Habsyi, op.cit., hlm, 51.)

2) Berperangai yang Lemah serta Lembut

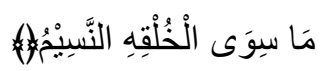

"Perilakunya yang lembut, selembut angin sepoi nan sejuk". (Ali bin Muhammad bin Husein al-Habsyi, op.cit., hlm, 50.) 
3) Mempunyai Tekad yang Kuat

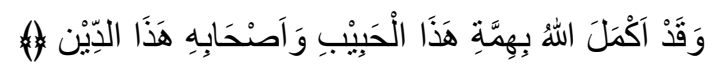

"Dan dengan tekad yang kuat nabi tercinta ini, demikian pula dengan para sahabatnya, Allah Swt berkenan menyempurnakan agama ini". (Ali bin Muhammad bin Husein Al-Habsyi, op.cit., hlm, 40.)

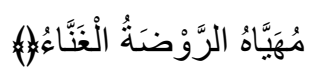

“Tegas dalam sikap, kuat dalam tekadnya”. (Ibid., hlm, 50.)

4) Zuhud

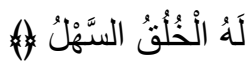

"Sederhana perangainya". (Ali bin Muhammad bin Husein Al-Habsyi, op.cit, hlm, 53.)

5) Dermawan

$$
\text { وَالْخُلْقُ مُقْسِطْ مِعْطَكَ }
$$

"Dan demikian pula akhlak yang disandangnya yaitu adil dan dermawan dimana pun ia berada". (Ali bin Muhammad bin Husein Al-Habsyi, op.cit, hlm, 51.)

6) Wibawa

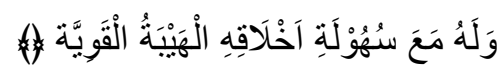

"Rendah hatinya namun cukup kuat wibawanya". (Ali bin Muhammad bin Husein Al-Habsyi, op.cit., hlm, 54.)

\section{Akhlak Santri di lingkungan Pondok Pesantren Darur Rohman Demak dan kehidupan sehari-hari}

\section{Dalam Hal Ibadahnya}

Dalam hal Ibadah santri menerapkan akhlak pembiasaan dan kedisiplinan. Ketika santri ke masjid, setiba didepan pintu dan sebelum memasuki masjid santri mengadahkan tangan, guna berdo'a sebelum masuk masjid. Kemudian santri masuk masjid mengunakan kaki kanan, dan melakukan sholat tahiyat masjid, dan berdzikir, hingga dikumandangkan adzan. Sembari adzan selesai santri mengadahkan tangan guna berdoa sesudah adzan, kemudian santri mengikuti jama'ah sholat hingga selesai, setelahnya santri dzikir bersama mengikuti imam. (Hasil wawancara dengan pengurus santri di pondok pesantren Darur Rohman Demak, pada hari sabtu 7 Maret 2020.) Setelah mengikuti kajian selapanan kitab 
maulid Shimt ad-Durar para santri diharapkan lebih rajin lagi dalam meningkatkan ibadahnya.

\section{Ta'dhim Kepada Kiyai dan Asatidz}

Sikap ta'dhim santri di pondok ketika salah satu santri dipanggil oleh kiyai atau guru langsung menghampiri dengan mengucapkan salam serta salim dan dicium tangan nya kiyai atau guru tersebut, disertai dengan kepala yang selalu menunduk mendengarkan dengan baik apa yang sedang di katakan oleh kiyai maupun gurunya, dan ketika mau beranjak pergi salim dengan mencium tangannya setelah itu mengucapkan salam dan berjalan tidak langsung membelakangi gurunya dengan kepala yang masih menunduk.

Bukan hanya itu saja akan tetapi sebagian santri dilibatkan langsung dalam acara mingguan yaitu pada acara setiap hari rabu sore untuk membantu konsumsi, humas dan sie acara lainya, dan semua santri dilibatkan dalam acara bulanan yaitu acara tiap malam jum'at pon untuk membantu konsumsi, humas dan sie acara lainya. Hal tersebut tentunya perintah langsung dari Kiyai dan santripun ta'dhim kepada perintah beliau. (Hasil wawanncara dengan pengurus santri di pondok pesantren Darur Rohman Demak, pada hari sabtu 7 Maret 2020.) Setelah para santri mengikuti kajian selapanan kitab maulid Shimt ad-Durar para santri diharapkan lebih mendalami sikap akhlak kepada kiyai maupun para asatidz khususnya dilingkup pondok pesantren Darur Rohman.

\section{Saling Menghormati Sesama Teman Santri}

Dengan adanya acara rutinitas harian, mingguan dan bulanan di pondok pesantren Darur Rohman yang melibatkan para santri untuk ikut serta membantu acara tersebut akan membuat para santri lebih aktif dan mengenal satu sama lain kepada teman-temannya dilingkungan pondok pesantren, karena tidak semua para santri itu sudah saling saling mengenal, dengan cara itu santri juga diajarkan untuk saling membantu, bergotong royong, dan menghormati kerjaan atau usaha orang lain.

Setelah para santri mengikuti kajian selapanan kitab maulid Shimt ad-Durar para santri diharapkan lebih rajin dan giat lagi untuk saling membantu urusan orang lain, baik itu di lingkungan pondok pesantren maupun di lingkungan masyarakat nantinya. (Hasil wawanncara dengan pengurus santri di pondok pesantren Darur Rohman Demak, pada hari sabtu 7 Maret 2020.) 


\section{Terhadap Keluarga Santri}

Ketika santri pulang kerumahnya kebetulan juga berdekatan dengan penulis, santri tersebut banyak sekali perubahan yang dulunya jarang sekali mencium tangan orang tuanya, setelah muqim di pondok pesantren ketika ijin pulang sesampainya di rumah mencium tangan kedua orang tuanya, dan juga berkata sopan, lebih giat belajar dalam hal menggali ilmu agamanya, rajin mengaji, dan rajin berjamaah di mushola. (Hasil wawanncara dengan wali santri di desa Banjarsari, pada hari Sabtu 7 Maret 2020.)

\section{Terhadap Tetangga}

Santri ketika pulang ke rumah yang di hormati bukan hanya keluarganya saja akan tetapi yang penulis lihat santri tersebut juga menghormati tetangganya, bersikap ramah, sopan, dan rajin membantu apapun itu entah roan, gotong royong, undangan khoul, hajatan, dan lain sebagainya. (Dokumentasi santri di desa Banjarsari, pada hari Sabtu 7 Maret 2020.) Hal tersebut sangatlah berbeda ketika sebelum mondok dulu, yang dulunya hanya sering di rumah kurang aktif di masyarakat bermalas-malasan dan pergaulanya yang kurang benar membuat orang tuanya untuk memondokkan anaknya tersebut dan sekarang mulai banyak perubahannya.

\section{Terhadap Temannya Ketika di Rumah}

Akhlak yang diterapkan santri dalam bergaul ketika di rumah bersama teman-temannya sangatlah tidak jauh dari akhlaknya ke keluarga dan ke tetangga yakni berkata sopan, jujur, saling bekerjasama yang baik ketika dalam suatu ormas, dan menasihati ketika ada yang salah. (Ibid.,) Ketika penulis menanyakan perubahan akhlak santri ke temannya mereka menjawab sangatlah banyak perubahan, dulu suka nongkrong tidak jelas, kurang sopan dan sekarang akhlaknya semakin baik kepada siapapun. (Hasil wawanncara dengan teman santri di desa Banjarsari, pada hari Sabtu 7 Maret 2020.)

\section{KESIMPULAN}

Nilai-nilai pendidikan akhlak yang ada di dalamnya adalah mengajarkan kepada setiap santri agar memiliki bertambahnya rasa menyucikan serta memuji Allah Swt, Memohon Ridho-Nya, bersyukur kepada-Nya. Nilai-nilai pendidikan akhlak yang ada di dalamnya juga mengajari para santri agar menjadi orang yang memiliki rasa akhlak 
terhadap Rasulullah Saw, Serta mengajari para santri agar menjadi orang yang memiliki rasa akhlak terhadap dirinya sendiri yaitu dengan cara memelihara kesucian lahir serta batin dan menahan diri dari sesuatu yang tidak disukai oleh Allah Swt, mempunyai rasa malu, berperangai yang lemah serta lembut, mempunyai tekad yang kuat, bersifar zuhud, bersifat dermawan, berwibawa.

Implementasi nlai-nilai pendidikan akhlak rasul dalam kitab maulid Shimt adDurar terhadap akhlak santri di pondok pesantren Darur Rohman, akhlak santri dalam kitab maulid Shimt ad-Durar di pondok pesantren Darur Rohman telah dilaksanakan dengan baik di lingkungan pondok pesantren khususnya pada aktifitas keseharian santri di lingkup pondok yang mengedepankan akhlak.

\section{DAFTAR PUSTAKA}

Ali bin Muhammad bin Husein Al-Habsyi, (1992). Untaian Mutiara Kisah Kelahiran Manusia Utama; Akhlak, Sifat dan Riwayat Hidupnya (Kisah Maulid Nabi Besar Muhammad SAW), Terj. Simtud Durar Fi Akhbar Maulid Khairil Basyar wa Ma Lahu min Akhlaq wa Aushaf wa Siyar, oleh Alwi bin Ali al-Habsyi. Solo: Sekretariat Masjid Riyadh.

Aminuddin, dkk. (2014). Pendidikan Agama Islam Untuk Perguruan Tinggi Umum. Bogor: PT. Ghalia.

Departemen Agama RI. (2009). Al-Qur'an dan Tafsirnya. Jakarta: Lembaga Percetakan Al-Qur'an Departemen Agama.

https://tafsirweb.com/7668-surat-al-ahzab-ayat-56.html, (diakses 26 November 2019).

M. Chabib Thoha, Kapita Selekta Pendidikan Islam, (Yogyakarta: Pustaka Pelajar, 1996)

Moleong, L.J. (2002). Metode Penelitian Kualitatif. Bandung: PT. Remaja Rosada Karya.

Nasharuddin, (2015). Akhlak, Jakarta: Raja Grafindo Persada.

Raharjo, dkk. (1999). Pemikiran Pendidikan Islam; Kajian Tokoh Klasik dan Kontemporer. Yogyakarta: Pustaka Pelajar. 